363 | janvier-mars 2011

L'Amérique du Nord à l'époque de la Révolution

française

\title{
Lettre inédite sur la situation à Saint-Domingue en
} novembre 1792

Jean-Charles Benzaken

\section{(2) OpenEdition \\ Journals}

Édition électronique

URL : https://journals.openedition.org/ahrf/11961

DOI : 10.4000/ahrf.11961

ISSN : 1952-403X

Éditeur :

Armand Colin, Société des études robespierristes

Édition imprimée

Date de publication : 1 mars 2011

Pagination : 169-173

ISBN : 978-2-200-92677-9

ISSN : 0003-4436

Référence électronique

Jean-Charles Benzaken, « Lettre inédite sur la situation à Saint-Domingue en novembre 1792 »,

Annales historiques de la Révolution française [En ligne], 363 | janvier-mars 2011, mis en ligne le 01 mars 2014, consulté le 22 avril 2022. URL : http://journals.openedition.org/ahrf/11961 ; DOI : https:// doi.org/10.4000/ahrf.11961 


\title{
LETTRE INÉDITE SUR LA SITUATION A SAINT-DOMINGUE EN NOVEMBRE 1792
}

\author{
Jean-Charles BENZAKEN
}

Le document inédit que nous présentons ici se trouve dans les Archives départementales des Bouches-du-Rhône, sous la cote L 506 ${ }^{1}$. C'est un document semi-officiel puisqu'il s'agit d'une lettre adressée au « Citoyen Président et citoyen Administrateur » du département des Bouches-du-Rhône, par quelqu'un qui, par ses relations familiales, les connaît sans doute personnellement. L'auteur en effet, Jean Baptiste Marie Guillermy, est né à Marseille le 28 décembre 1760. Il est le fils légitime de sieur Guillaume Étienne Guillermy et de dame Claire Julien et a été baptisé dans l'église de la paroisse marseillaise de Saint-Férréol. Sa famille appartient au milieu du commerce, elle compte des courtiers en denrées coloniales. Son père était négociant. Ce fils de famille, que le commerce et le travail en général n'intéressait guère, désespérait ses parents, qui, lassés de sa conduite finirent par l'expédier à Saint-Domingue avec une pacotille sur le navire La Ville de Marseille, qui appareilla de la cité phocéenne le 16 janvier 1789, pour le Cap-Français, dans le nord de Saint-Domingue (source : CAOM F5B 2). Il avait donc 29 ans.

Malheureusement le jeune homme ne s'amenda pas, ne trouva pas de travail stable et devint commis guichetier du geôlier dans les prisons de Saint-Marc. L'arrivée des commissaires nationaux civils Sonthonax, Polverel et Ailhaud fut pour lui une chance, car ce dernier était provençal comme Guillermy et connaissait sans doute sa famille. C'est ainsi que Jean Baptiste Marie put l'approcher et, à force de démarches, parvint

(1) Pour aller plus loin, le lecteur pourra se reporter au Rapport sur les troubles de SaintDomingue, fait au nom de la commission des colonies, des comités de salut public, de législation et de marine réunis, Paris, an V-VII, par Garran-Coulon, notamment les tomes 1, 2 et 3. 
à devenir le « secrétaire adjoint de la Commission nationale civile déléguée à Saint-Domingue », et plus modestement le secrétaire personnel du commissaire national civil Ailhaud.

Quoi qu'il en soit, et c'est là l'intérêt de cette lettre il se trouvait en contact direct et journalier avec les nouvelles autorités de l'île envoyées pour y rétablir l'ordre et la tranquillité; et l'époque où cette lettre a été écrite nous semble aussi importante car il s'agit du début de leur mission.

Voici le texte de la lettre :

«L'Orient [Lorient] le 23 décembre, l'an premier de la République française

Citoyen Président et citoyen Administrateur

J'arrive de Saint-Domingue que j'ai quitté le 20 du mois passé avec le citoyen Ailhaud, l'un des trois Commissaires nationaux envoyés dans cette île infortunée et que j'accompagne dans sa mission. Je vais vous instruire le mieux qu'il me sera possible de la situation de cette partie française, sur laquelle notre ville a le plus grand intérêt d'avoir toujours l'œil ouvert; l'amour de ma patrie m'y engage et mon devoir me le prescrit.

Vous aviez sans doute été informé du détail de l'embarquement du sieur Cambefort et ses adhérents, Blanchelande et D'Esparbés, il est bien sûr que les citoyens patriotes ont donné le plus grand exemple de prudence dans la journée du 19 octobre et les quatre hommes tués ne l'eussent pas été s'ils n'avaient attaqué les premiers. Il est même admirable pour l'humanité que tous ceux qui portaient l'uniforme de Condé n'aient pas été livrés à la fureur assurément bien juste d'un peuple outragé, après ce qui venait de se passer dans la ville. Quelques personnes eurent des craintes pour elles, mal fondées, les uns demandèrent des passeports pour aller à la Nouvelle Angleterre, les autres pour France, ce qui leur fut accordé par les Commissaires nationaux.

Rien d'intéressant ne s'est passé au Cap, jusqu'à notre départ qui eut lieu le 29 du même mois, pour nous rendre dans la partie de l'Ouest que le remplacement des embarqués du Pouvoir exécutif, et le citoyen Rochambeau désiré des troupes, a remplacé le Sr. D'Esparbès; mais je vous apprendrai l'amertume dans le cœur, citoyens, que nos braves défenseurs qui ont quitté leurs foyers pour s'expatrier sont dévorés par le climat, par les mauvais aliments et par des boissons que je doute n'être point falsifiées, déjà la mort nous a enlevé les deux cinquièmes de cette belle jeunesse et nous n'avions à cette époque aucun avantage encore de remporté sur les révoltés. 
Arrivé à Saint-Marc, avec les citoyens commissaires Polverel et Ailhaud, nous avons eu le désagrément de voir que la loi a été méconnue par la moitié des habitants de cette ville : quelques insurrections dans le morne voisin demeuré tranquille jusqu'alors se sont manifestées; mais nous avons appris par la suite que l'on avait remédié au mal.

Nous avons appareillé le 8 novembre pour nous rendre au Port-auPrince que nous avons trouvé assez tranquille, sa plaine dans un bon ordre apparent, car on ne voit plus les ateliers travailler dans cette crainte et ce respect comme ci-devant, et j'ai vu par mes yeux de grands relâchements parmi les esclaves soit pour se rendre au travail, soit pour l'exécuter.

Nous n'avons pas eu de grands détails sur la partie du Sud et encore moins des Cayes; mais nous croyons la position de cette ville alarmante pour le nombre considérable de révoltés qui sont campés dans ses environs et qui continuent une hostilité malgré qu'on leur ait donné un grand nombre de libertés. Voilà le vrai tableau en gros de la position des trois provinces de Saint-Domingue.

Pour réduire les révoltés de cette colonie et faire disparaître tous les malheurs dont elle est menacée, je pense qu'il faudrait une force très imposante et faire une attaque générale et combinée pour le même instant dans tous les quartiers insurgés, où l'on puisse, si les fermiers [?] veulent épargner le sang de leurs esclaves, tout au moins les désarmer à la fois et faire un exemple des chefs; il faut encore calculer que si vous envoyez 40000 hommes à Saint-Domingue, vous ne devez compter que sur 24000 pour l'instant où ils seront répartis par tous les postes et en état d'attaquer. Cette force, je vous l'assure ne serait pas suffisante, et je vous laisse à penser encore ce qu'elle coûterait à la république, assurément non, elle ne serait pas suffisante par la division qui règne encore dans l'esprit des habitants de Saint-Domingue, mais elle serait au contraire plus qu'imposante si, premièrement, l'administration renonçait entièrement à l'espoir chimérique de contre-révolution, et se vouait au bien de la patrie, si quelques membres de l'ancien pouvoir judiciaire et ses adhérents cessaient de souffler le feu de la discorde, si enfin chacun se disait à lui-même, je veux le bien et m'y sacrifie.

Permettez-moi, Citoyens, ces réflexions qui ne peuvent échapper à un patriote qui a vu Saint-Domingue et qui a vécu depuis le commencement de la Révolution jusqu'à l'époque où nous avons appareillé de Port-auPrince sur la frégate la Sémillante, commandée par le citoyen Bruix, et mouillée en cette rade le 20 du courant. Nous avons appris avant notre départ que le citoyen général Rochambeau avait emporté sur les révoltés 
le poste d'Ouanaminthe dans la partie du Nord. Ce poste voisin du FortDauphin est très avantageux pour nous.

S'il est quelques-unes de vos questions, citoyens, auxquelles je puisse satisfaire, je serai rendu dans trois ou quatre jours à Paris avec le citoyen Commissaire Ailhaud, où je serai à même par lettre de satisfaire à vos désirs, à moins que la circonstance me déterminassent [sic], après le compte que nous devons rendre, de me permettre d'aller voir ma famille, dans tous les cas où notre mission serait finie : dans ce cas je me ferai un devoir de vous instruire du plus petit détail.

Je suis avec respect, Citoyen Président et Citoyen Administrateur, Votre très humble et obéissant serviteur

Guilhermy, secrétaire adjoint de la Commission nationale civile déléguée à Saint-Domingue ».

Lorsqu'il écrit à ses correspondants, Guillermy sait bien que les informations concernant la colonie de Saint-Domingue, de par leurs relations commerciales avec le grand port phocéen, les intéressent au plus haut point, car celles qu'il leur offre sont des nouvelles fraîches et puisées à la meilleure source. Il se ménage ainsi après son retour à Marseille la possibilité d'obtenir un emploi.

Guillermy insiste sur les incessantes dissensions entre les blancs qui occasionnent des troubles graves partout dans la colonie. Il cite en particulier, les événements d'octobre 1792 au Cap et la proscription des royalistes, dont l'ancien gouverneur Blanchelande et son successeur D'Esparbès, par les commissaires civils à l'instigation des colons « patriotes » au Cap, qui sont bien connus par ailleurs.

Viennent ensuite les nouvelles concernant les opérations militaires et par conséquent l'armée, particulièrement les troupes métropolitaines envoyées pour combattre les esclaves insurgés, qui sont en position de force. Elles sont sans énergie car disséminées un peu partout sur l'île et surtout elles sont décimées par les maladies tropicales et mal ravitaillées. Ces faits sont également bien connus.

Bien plus intéressante à nos yeux est l'opinion très négative de Guillermy sur la situation de la colonie en décembre 1792 déjà, d'autant plus intéressante qu'elle doit refléter celle d'Ailhaud, bien évidemment, mais également celle des deux autres commissaires nationaux civils, Sonthonax et Polverel. La victoire militaire sur les noirs révoltés est impossible ou alors elle a un prix exorbitant que la métropole ne peut pas payer : Il faudrait envoyer un tel corps expéditionnaire que la République française, assiégée partout en Europe n'en aurait pas la capacité. 
Et le général Leclerc sous le Consulat connaitra l'échec et la mort que l'on sait...

Les informations contenues dans cette lettre permettent ainsi de mieux comprendre la décision prise par Sonthonax et Polverel, de rechercher un accord avec les insurgés, et d'accorder la liberté générale quelques mois plus tard, dans l'été 1793, aux esclaves.

Jean-Charles BENZAKEN Docteur en Histoire fabienneb83@orange.fr 